
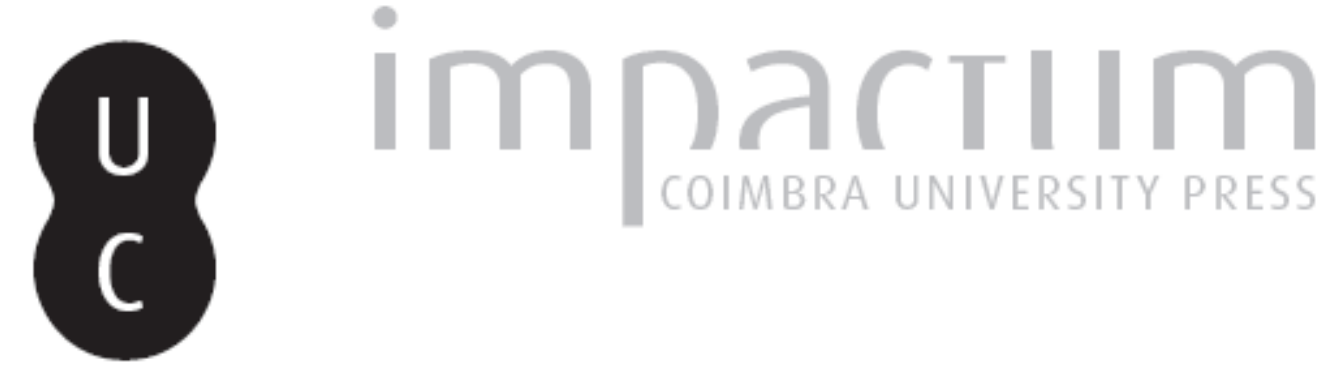

\title{
Sabores y sinsabores de un programa darwinista para las Ciencias Sociales
}

Autor(es): $\quad$ Francesch, Alfredo

Publicado por: CIAS - Centro de Investigação em Antropologia e Saúde

URL persistente:

URl:http://hdl.handle.net/10316.2/28622

DOI:

DOI:http://dx.doi.org/10.14195/2182-7982_27_1

Accessed : $\quad$ 26-Apr-2023 02:56:47

A navegação consulta e descarregamento dos títulos inseridos nas Bibliotecas Digitais UC Digitalis, UC Pombalina e UC Impactum, pressupõem a aceitação plena e sem reservas dos Termos e Condições de Uso destas Bibliotecas Digitais, disponíveis em https://digitalis.uc.pt/pt-pt/termos.

Conforme exposto nos referidos Termos e Condições de Uso, o descarregamento de títulos de acesso restrito requer uma licença válida de autorização devendo o utilizador aceder ao(s) documento(s) a partir de um endereço de IP da instituição detentora da supramencionada licença.

Ao utilizador é apenas permitido o descarregamento para uso pessoal, pelo que o emprego do(s) título(s) descarregado(s) para outro fim, designadamente comercial, carece de autorização do respetivo autor ou editor da obra.

Na medida em que todas as obras da UC Digitalis se encontram protegidas pelo Código do Direito de Autor e Direitos Conexos e demais legislação aplicável, toda a cópia, parcial ou total, deste documento, nos casos em que é legalmente admitida, deverá conter ou fazer-se acompanhar por este aviso.

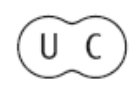




\section{Antropologia Portuguesa}

Volume $26-27 \cdot 2009-2010$

Departamento de Antropologia | Universidade de Coimbra

DARWINISMO:

revisitações, propostas, problemas 


\title{
Sabores y sinsabores de un programa darwinista para las Ciencias Sociales
}

\author{
Alfredo Francesch \\ Departamento de Antropología Social y Cultural \\ Universidad Nacional de Eduación a Distancia, España \\ afrancesh@fsof.uned.es
}

Resumen El pensamiento darwiniano ha inspirado diversas corrientes en las ciencias humanas y sociales, que pueden considerarse, en perspectiva, estadios sucesivos de un único programa de investigación. Este texto pretende sintetizar las aspiraciones de este programa y trata de revisar la validez de sus planteamientos de base, en el plano teórico y el epistemológico.

Palabras clave Darwin; selección natural; evolucionismo; sociobiología; psicología evolutiva.

Resumo $\mathrm{O}$ pensamento darwiniano inspirou diversas correntes das ciências humanas e sociais, que podem considerar-se, em perspectiva, estados sucessivos de um único programa de pesquisa. Este texto pretende sintetizar as aspirações deste programa e rever a validade das metodologías de base tanto a nível teórico como epistemológico.

Palavras-chave Darwin; selecção natural; evolucionismo; sociobiologia; psicologia evolutiva.

\section{Humanos pero animales}

Dícese que una aristócrata victoriana en cierta ocasión comentó: "espero que no sea verdad lo que dice Darwin. Pero, si es verdad, que no se entere nadie". Las esperanzas humanas, está visto, resultan frustradas con frecuencia ${ }^{1}$.

El legado de Darwin admite distintas lecturas y también muy distintas valoraciones -no podía ser de otro modo, como ilustra esta dama-, de las que, con sólo un somero vistazo a la numerosa literatura existente se puede obtener una idea suficientemente ajustada. En términos generales,

\footnotetext{
${ }^{1}$ No recuerdo dónde encontré esta anécdota, por lo que espero que se me perdone una cita sin su obligatoria referencia y hecha de memoria.
} 
lo que parece obvio, pues estas mismas páginas lo ponen de manifiesto, es que el brillo de su figura ha sido bastante como para oscurecer a toda una constelación de intelectuales que, dentro y fuera de la academia, habían centrado su atención en cuestiones muy similares a las que dieron a Darwin su fama. Por así decirlo, en él convergieron una serie de condiciones que lo catapultaron a la inmortalidad, dejando muy atrás incluso a Wallace, que a la postre elaboró planteamientos teóricos muy semejantes y casi simultáneamente.

El nombre de Charles Darwin está automáticamente vinculado al término "evolución". Pero lo cierto es que su obra de mayor relieve no trata en exceso de evolución, sino más bien de selección; que la palabra "evolución" ni siquiera figuraba en el texto hasta posteriores reediciones, ni figura en el título; y que Darwin no fue el primero en reflexionar sobre la evolución. Lo que viene a decir que el renombre puede crearse en paralelo a la forma en que sucedieron las cosas.

Pero lo que, sin asomo de dudas, constituyó uno de los núcleos conceptuales de la teoría darwiniana y, sin muchas dudas, era novedoso (aunque no completamente) fue la nueva posición del ser humano como consecuencia del planteamiento evolutivo: un animal mas, uno de tantos, inmerso en los procesos biológicos terrestres como cualquier otro, desde el más viscoso equinodermo a la espectacular ave lira. En verdad las intuiciones de Darwin en este punto fueron acertadas, desde el momento en que, careciendo de excesivo fundamento para hacerlo, afirmó el origen africano de nuestros antepasados. Y, del mismo modo, fue coherente con sus propios planteamientos siguiendo su lógica hasta el final, fueran cuales fueren las conclusiones. El contrapunto ofrecido por Wallace en este sentido no deja lugar a dudas. Si bien es cierto que no toda la teoría darwiniana es también teoría wallaciana (ahí está, por ejemplo, el mecanismo de selección sexual), el hecho de que una buena proporción de sus controversias derive de la posición humana en nuestro ajetreado planeta nos sitúa en una buena localidad para apreciar el significado de este elemento de la teoría de Darwin².

Suele considerarse en la historia de la ciencia la existencia de un proceso de humildad, por así llamarlo, que desalojó a los seres humanos del centro del universo (en la época de los cimientos de la astrofísica) y continúa

${ }^{2}$ Sobre este debate entre Darwin y Wallace, puede verse el ameno texto de Gould (2005 [1981]). 
desalojándolo de la cúspide de la Creación, por mor de Darwin. Y como la humildad decidida por otros no suele ser bien acogida por uno mismo, parece bastante razonable entender que la nueva situación de los seres humanos no resultara del todo satisfactoria para muchos. Resulta que a, la postre, somos uno de tantos organismos, surgidos al albur de los mecanismos evolutivos (conforme al gradualismo filético, bastante azarosos), por igual sometidos al filtro inapelable de la selección natural, con sus garras y colmillos ensangrentados; organismos contingentes, en absoluto necesarios, efímeros... Es jugar con estas cosas lo que, presumo, llevó a Dennet (1995) a titular uno de sus libros La peligrosa idea de Darwin. Es cierto que lo que existen no son peligros en sí, sino percepciones de peligro, lo que llevaría a la necesidad de una modificación del título de Dennet en aras de la precisión, pero esto nos llevaría a un cierto detrimento de su capacidad de impacto...

Lo que en este punto nos interesa es que, desde el momento en que los seres humanos deben ser considerados uno más de entre tantos animales, el programa propuesto para la investigación social y antropológica cobra un relieve posible. Producto de centenares de miles de años de evolución y selección, por limitarnos a antepasados cercanos y no remitirnos a cientos de millones de años, el ser humano presenta un acabado biológico que debería entenderse desde este enfoque. Pero, adicionalmente, dado que el universo social y cultural de los humanos es producto de su actividad cerebral, producto a su vez, del mecanismo doble y sucesivo de evolución/ selección, ¿no sería pertinente tratar los hechos del dominio sociocultural bajo el prisma neodarwiniano?

Todo un programa de investigación (Lakatos, 1998 [1978]) se ofrece posible, en estos parámetros, con el sano propósito de constituir una ciencia del ser humano sobre cimientos de impecable pedigrí científico y materialista. Las ciencias sociales, pobladas por entidades enigmáticas como "fuerzas", "imaginarios colectivos", en el peor de los casos, pero, incluso en el mejor, pobladas por entidades siempre sospechosas, como "estructuras", "matrimonio" o "intercambio recíproco", podrían liberarse de estos rótulos que, en ocasiones, incluso despiden un cierto tufillo animista. Evolución, selección, ventajas selectivas, genomas, parecen, en principio, contar con una existencia ontológicamente más firme (Sperber, 2005 [1996]). 


\section{Sociobiología}

El primer envite de este programa llegó, por enmarcarlo de manera más o menos precisa, en la década de los setenta del pasado siglo, con el gradualismo filético instalado en un trono cómodo y un poderoso crecimiento de la etología en el escenario (figuras señeras como Lorenz, Tinbergen, Goodall, por dar algunos nombres heteróclitos). En 1977, poniendo un jalón en esta ruta, se fundó en Estados Unidos la Internacional Society for Human Ethology, de la que fue presidente durante un buen numero de años Irenäus Eibl-Eibesfeldt. Pero el programa fuerte vino, como es bien sabido, desde la sociobiología ${ }^{3}$. Los sociobiólogos siempre se consideraron inmersos dentro del paradigma darwiniano y sus intereses abarcaban desde los insectos a los seres humanos. Este último aspecto es el que aquí nos interesa.

El caso es que la obra madre del programa, Sociobiología (Wilson, 1980 [1975]), tampoco se presta a un alboroto exagerado. De las aproximadamente 700 páginas de su edición española, apenas unas treinta están específicamente destinadas a la especie humana y sus postulados no son demasiado espectaculares ${ }^{4}$. Posiblemente, gran parte de la repercusión de la obra está más bien provocada por los propósitos y las previsiones de futuro de su autor. Augura una fusión de las ciencias sociales que sería seguida de la deglución del producto resultante por parte de la Biología (p. 593).

El programa tal vez esté más claro en la obra de Ruse (1989 [1980]). Según este autor, el guión a seguir es sencillo. Dado que "los animales y los seres humanos comparten muchos atributos" (p. 204):

"[...] se debe comenzar con el individuo humano como una entidad biológica: lo que a su vez significa que se debería intentar entender en última instancia las cosas en términos del interés reproductivo del individuo humano... por consiguiente, la cultura debe ser considerada en algún sentido como adaptativa para el individuo humano... nueva información adaptativa puede ser transmitida directamente de fenotipo a fenotipo sin tener que pasar a través del genotipo. Esta forma de transmisión [...] tiene un poder adaptativo global en el sentido de que es mucho más rápida que los métodos tradicionales del cambio revolucionario" (pp. 243-4).

${ }^{3}$ Dennett (1995) postula un linaje para la sociobiología tan ilustre como secular, con Hobbes como primer sociobiólogo.

${ }^{4}$ Omitiremos algunas profecías de las últimas páginas. 
En definitiva, “[...] el problema que se discute es el de saber en qué medida el comportamiento humano, en especial el comportamiento social, es esencialmente una función de los genes" (p. 184) (cursiva mía). Esta definitiva propuesta de Ruse contiene algo de sorprendente. Parece, en principio, no encajar bien con las cautelas que plantea el propio Wilson cuando cita a Dobzhansky (1963):

[...] la cultura no se hereda a través de los genes, se adquiere mediante el aprendizaje a partir de otros seres humanos... En cierto sentido, los genes humanos han capitulado su supremacía en la evolución humana, ante un agente completamente nuevo, no biológico o superorgánico, que es la cultura ${ }^{5}$.

Pero, en cualquier caso, el programa ya estaba ahí. Recibió críticas de todo tipo y, en buena medida, el combate teórico se transformó en combate ideológico, planteado en términos de política, en lo que suele entenderse como "derecha" e "izquierda". Las acusaciones de feroz derechismo fueron, en general, respondidas planteando error de base: la sociobiología no derivaba necesariamente hacia un pensamiento político derechista. Sólo algunos autores más virulentos se han defendido de esas críticas sosteniendo un "sí, a mucha honra", seguido de un "y ustedes son aún peores". El caso más notable de esta posición sería, posiblemente, el de Pinker, sociobiólogo de segunda generación -si se me permite esta categorización sui generis-.

Conforme a Pinker (2003 [2002]), Pol Pot, los gulags y otras pesadillas sociales son producto directo de la negación de las ideas del programa de antropología darwinista. Es cierto que esta inferencia convive, extrañamente, con el hecho de que la aceptación de ese mismo programa tenga resultados similares en formas de campo de exterminio nazi y otras lindezas. Pero, en alambicada argumentación, Pinker logra sostener a la vez que $\neg p \rightarrow q \mathrm{y}$ $p \rightarrow q$, que afirmación y negación conducen a los mismos resultados. Se trata, naturalmente, de que los "nazis" hicieron mal uso de la biología, mientras que los jemeres hicieron uso correcto de sus propias ideas. Si he entendido bien a Pinker, los genocidios nazis no son coherentes con el pensamiento

\footnotetext{
${ }^{5}$ No quisiera soslayar la referencia, intencionada o no, a lo "superorgánico" de Kroeber
} (1917). En cualquier caso, no figura en las referencias bibliográficas. 
nazi, pero los genocidios stalinistas son completamente coherentes con el pensamiento stalinista ${ }^{6}$.

Soslayando estos detalles, con la ventaja que otorga el paso del tiempo, y dejando de lado un análisis de la sociobiología en términos políticos, podemos ahora rastrear lacras del programa lo suficientemente pesadas como para lastrar su andadura y que, a la postre, lo han dejado aparcado en una ubicación mucho menos protagonista que aquella augurada por los más entusiastas. No se olvide que, si el gradualismo filético sintetizó darwinismo y genética de poblaciones, la "nueva síntesis" sociobiológica quiso sintetizar neodarwinismo con ciencias sociales. En resumen, darle a las ciencias sociales el marchamo científico del que, al parecer, siempre habían carecido. Un propósito de innegable ambición que no se ha visto, hasta la fecha, cumplido?.

Un ejemplar de razonamiento sociobiológico podría tener los siguientes pasos:

a) Un comportamiento social esta generalizado.

b) Si esta generalizado, debe de contar con ventajas adaptativas.

c) Si cuenta con ventajas adaptativas, debe de estar inserto en el genoma.

En buena, medida, todos y cada uno de los puntos carecen de los deseables requisitos de solidez cuando se pone uno a la práctica. Sigamos, por ejemplo, los consejos de Desmond Morris y eliminemos del espectro de comportamientos los realizados por cualquier sociedad que no sea la llamada "occidental", puesto que, al parecer, es la única a la que podemos considerar más apta, por ser la superviviente ${ }^{8}$. Una vez eliminados estos, de entre los posibles, elijamos uno. Por ejemplo, algunos de los propuestos por

${ }^{6}$ Adicionalmente, siempre queda la posibilidad de que el comunismo tenga un origen genético. En los años setenta, el fiscal general de Estados Unidos, William Saxbee, declaró en cierta ocasión que "los genes determinantes del comunismo tienden a agruparse con mayor frecuencia en familias judías" (Woodward, 1982 apud Sandín, 2000).

${ }^{7}$ Para críticas más o menos coetáneas a la aparición de la sociobiología, hechas desde la antropología, pueden verse textos muy conocidos como Lewontin, Rose y Kamin (1996 [1984]), Harris (1982 [1979]) o Sahlins (1982 [1976]).

${ }^{8}$ Según Morris, una de las fuentes de material empírico para su tarea fue la observación de normas conductuales de "los ejemplares evolucionados de las principales culturas contemporáneas", dado que las que puedan detentar "los sencillos grupos tribales" actuales, en tanto que forman grupos sociales que han "fallado", se "han extraviado", no tienen la menor relevancia. Se trata de que estas gentes "no son primitivos, sino que están embrutecidos". 
Pinker en la lista de universales humanos que recoge de Donald E. Brown (1991 apud Pinker, 2003 [2002]): la tacañería9.

Quisiera, en primer lugar, acentuar el hecho de que este paso inicial está lleno de protocolos claramente arbitrarios. Determinar que una conducta determinada tiene un carácter universal es de un optimismo rayano en la candidez. Disponemos de informes sobre la vida humana desde hace, como mucho, unos pocos miles de años, desde el invento de la escritura (difícilmente puede haber alguno anterior). Cierto que los paleoantropólogos suelen inferir de las condiciones de vida de algunas poblaciones indígenas contemporáneas atributos que predicar de los humanos ancestrales. Y cierto, también, que podemos realizar inferencias a partir del depósito fósil y arqueológico. Pero en modo alguno podemos afirmar que tal o cual comportamiento tenga carácter "universal" en nuestra especie, de la que ignoramos casi todo durante más de cien mil años. Debemos imaginar que, por ejemplo, la caza era practicada de manera generalizada. Pero no podemos hacer la más mínima afirmación sobre "universales" como la tacañería, o tantos otros de los propuestos por tantos otros autores ${ }^{10}$.

Dando por evidente que el primer paso del razonamiento es más que dudoso en cuanto a su rigor, el segundo adolece de las mismas carencias: una completa falta de perspectiva temporal. Incluso aceptando que la tacañería pueda aceptarse como universal, no veo la menor conexión entre ese hecho y las supuestas ventajas adaptativas de la costumbre en cuestión. Si, por cualquier motivo, a excepción de catástrofes exógenas del tipo de una invasión de extraterrestres letales, la especie humana se extinguiera en, digamos, treinta mil años, su paso por el planeta habría sido especialmente efímero. La especie podría juzgarse, por un hipotético biólogo no humano del futuro, como un completo fracaso evolutivo. ¿Cuáles de los rasgos humanos habrían sido ventajosos, desventajosos o neutros? No creo que haya manera de saberlo. No disponemos de medio alguno para saber si nuestra especie sobrevivirá

\footnotetext{
${ }^{9}$ No debe buscarse un propósito maligno en mi empleo de la tacañería como ejemplar ilustrativo. Quien lo prefiera, puede optar entre otras posibilidades de la misma lista, como dar direcciones, hacer regalos, el uso de morfemas, la identidad colectiva o el complejo de Edipo; también puede utilizar cualquier otro elemento consultando la lista o utilizar otra lista, prescindiendo de las peculiares cautelas de Morris.

${ }^{10}$ Por lo demás, este tipo de cosas a mí me ofrece problemas lógico-formales. Si la tacañería es rasgo universal de la conducta humana, o ser humano es ser tacaño, ¿qué ocurre con los que no son tacaños? ¿No son humanos?
} 
durante un millón de años o así, para poner una longevidad razonable en una cronoespecie. Tampoco para saber qué elementos de nuestra conducta puedan ser determinantes para la supervivencia durante un millón de años. Consecuentemente, no disponemos de elementos de base para saber si tal o cual conducta debe ser juzgada como ventajosa o desventajosa. Imaginar ventajas adaptativas en algo sólo porque está presente es dar por supuesto que nuestra especie no será un fracaso evolutivo. Y se basa, además, en un circular razonamiento tautológico, conforme al cual un rasgo $r$, si está, es porque muestra ventajas selectivas, y estas ventajas selectivas son demostrables porque $r$ está $^{11}$.

No deja de ser cierto que algunos de los rasgos acaso ventajosos podrían ser rasgos derivados, plesiomorfias heredadas de, digamos, Homo ergaster $\mathrm{o}$ cualquier otra especie, que sí pudieron ser eficaces para este pariente filogénico. Pero nos debemos resignar a la ignorancia sobre la eficacia adaptativa del rasgo de conducta en cuestión, cuando se da bajo nuevas circunstancias. Pongamos que un determinado rasgo conductual, por ejemplo, la capacidad para la agresión intraespecífica, pueda haber tenido ventajas selectivas para un cardinal concreto de Homo ergaster, diseminadores de esa conducta entre su progenie, en tanto que los individuos carentes de ese rasgo hayan dispuesto de un inferior diferencial reproductivo. Su pervivencia hasta nuestros días haría que ese rasgo conductual entrara en juego con una capacidad para el pensamiento simbólico que, en principio, podemos postular superior en Homo sapiens que en Homo ergaster. Podrían darse propiedades emergentes. Esa capacidad para el pensamiento simbólico, por poner un ejemplo algo grosero, es causa de la elaboración de lenguaje con facultades abstractas, escritura, matemáticas, física, bombas atómicas y la no imposible eventualidad de que la humanidad sea borrada de la faz de la tierra en una guerra termonuclear. ¿Podríamos considerar que la capacidad agresiva habría sido ventajosa para nuestra especie, una vez destruida? De hecho, Wilson, aunque sin utilizar ejemplos tan trágicos, propone estas mismas cautelas a la hora de adjudicar ventajas selectivas a uno o otro rasgo (Wilson, 1980: 593).

Es este un problema no menor, ya señalado por numerosos autores: la validez lógica del seleccionismo, que parece inclinarse hacia lo tautológico, dando por hecho que lo que hay es lo selectivamente ventajoso y lo selec-

${ }^{11}$ Castrodeza (2009) llama a esto, cariñosamente, la "perogrullada" de Darwin. Cervantes (2008) utiliza el mismo término. 
tivamente ventajoso es lo que hay, como ya en su día comentaron Gould y Lewontin (1979). Un síndrome panglossiano, que humorísticamente suele describirse como la admirable sabiduría de la madre Naturaleza, que nos ha dotado de narices para que podamos llevar gafas. Para, pongamos por caso, tiburones o bacterias podemos dar por evidente el éxito evolutivo. En este caso es factible el análisis de rasgos eficaces y con ventajas selectivas. Cuando el tiempo de una especie es tan corto como el de la nuestra, encuentro un tanto aventurado juzgar si un determinado rasgo de conducta es eficaz o no. Incluso los rasgos heredados entran en un terreno comprometido, aunque algunos de ellos parezcan pasar el examen. Yo diría, por ejemplo, que ser bípedo es un rasgo con ventajas selectivas (si bien es, desde luego, una conducta no estrictamente biológica, porque a andar se aprende). Pero la capacidad heurística de esta perspectiva del bipedismo humano se me antoja un poco escasa.

El tercer paso no es menos resbaladizo. La cuestión "genética" ha resultado ser bastante más complicada de lo que uno se podía prometer hace unas décadas. Los vínculos que van de gen a conducta resultan cualquier cosa menos claros y más parecen propios de novela naturalista que de otra cosa. Está, por poner un caso, la enorme cantidad de material "basura" del genoma humano, que sorprendió a la comunidad científica; pero también está que, al final, parece que esta basura no es tan basura como parecía y reclama un papel activo. En definitiva, que el conocimiento actual de nuestro material genético es más un indicio de posibles conocimientos futuros que el colofón de una larga tarea. Lo que realmente sabemos es que no sabemos demasiado, y lo publicado en Nature cuando apareció el primer informe sobre la secuenciación del genoma humano, en el aún no tan lejano 2001, no permite albergar dudas a este respecto: "it is has not escaped our notice that the more we learn about the human genome, the more there is to explore" (International Human Genome Sequencing Consortium, 2001: 914).

Con este marco, ¿dónde se sitúa, físicamente, el origen genético de una conducta? ¿En un gen? ¿En varios? ¿En otro material genómico? ¿Qué significa eso? ¿Qué, si pudiéramos aislar ese material, produciría necesariamente esa conducta? Pero, ¿es siquiera imaginable ese test? ¿Es imaginable la actividad de porciones del genoma en completo aislamiento del restante material genómico y de su entorno? ${ }^{12}$ Porque, si esta última

${ }^{12}$ Cf. Ramírez-Goicoechea (2009). 
pregunta se responde con un no, ¿qué información tendríamos entonces? ¿De tipo estocástico?

Presumo que el enunciado resultante de estos tres pasos sería algo así como: "la tacañería se asocia probablemente a los elementos del genoma $x$, $y, z, \ldots, n$, en forma tal que existe una determinada probabilidad $p$ de que se ponga en práctica, en función de ciertas variables del entorno y de ciertas variables sistémicas del genoma, difíciles de precisar". Muchas alforjas para poco camino.

\section{La segunda generación}

La segunda generación del programa darwinista en las ciencias sociales ha matizado notablemente muchos de los propósitos de la primera, evitando así ser motivo de las mismas críticas. En líneas generales, sus propuestas vienen dadas por la psicología evolutiva y autores como el ya citado Pinker, además de Sperber, Barkow, Cosmides y Tooby, Buss, o Castro-Nogueira, Castro-Nogueira y Castro-Nogueira, por citar algunos.

El propósito parte de una reflexión sobre el modelo de ciencias sociales vigente, conforme a estos autores. Naturalmente, puede surgir la sospecha de que este modelo es más bien como uno de esos muñecos que se montan en algunas fiestas populares para posteriormente ser vapuleado por los alegres festejantes. Pero esta sospecha es inevitable, porque la elaboración de un modelo siempre incluirá características que el trabajo de uno no comparte y carecerá de otras que el trabajo de uno sí presenta.

No considero oportuno en este momento tratar las reflexiones de estos y otros autores sobre ese modelo. En parte, por el carácter inevitablemente arbitrario que siempre alberga la ambiciosa pretensión de construir un modelo de ciencias sociales vigente, lo que, por fuerza, conduciría a una no menor arbitrariedad en su examen. En parte, porque tampoco plantean las mismas cuestiones Pinker, Sperber o Dennet, lo que nos llevaría a la construcción de un modelo arbitrario de modelo arbitrario sobre el que dirigir el análisis.

Estas limitaciones nos llevan más bien a observar las propuestas metodológicas, epistémicas y teóricas, que, en mi opinión, sí presentan una mayor analogía, una mayor uniformidad, sin perjuicio de las lógicas diferencias que se pueden encontrar en una corriente que quiere enraizarse desde Darwin hasta hoy, como mínimo. 
Espero no deformar el programa si propongo que presenta las directrices siguientes:

a) Existe una naturaleza humana, consistente en una determinada configuración psicobiológica del Pleistoceno, que debe entenderse como resultado de la selección natural;

b) Existe conducta sociocultural humana, necesariamente construida sobre bases psicobiológicas y dependiente, en consecuencia, de la selección natural;

c) Si se consigue precisar los retos adaptativos que nuestros antepasados filogénicos tuvieron que afrontar, entonces se consigue dar razón de esa configuración psicobiológica.

El programa de segunda generación trata de eludir una secuencia inferencial del estilo genotipo $\rightarrow$ fenotipo $\rightarrow$ conducta, teñida de dawkinsismo, en la cual los fenotipos no sean sino máquinas transmisoras de genotipos (Dawkins, 1993 [1976]). De hecho, hasta el vehemente Pinker inicia el libro citado de una manera notablemente mesurada -aunque, según el texto va avanzando, ceda paulatinamente a su entusiasmo habitual ${ }^{13}-$, al precisar:

"No rebato, como algunos suponen, una postura extrema en defensa de la "educación" con otra postura extrema en defensa de la "naturaleza", pues la verdad se encuentra en algún lugar intermedio. En algunos casos, es correcta una explicación ambiental extrema: un ejemplo evidente es la lengua que uno habla, y las diferencias entre las razas y los grupos étnicos en las puntuaciones de los test quizá constituyan otro. En otros casos, como en determinados trastornos neurológicos heredados, será correcta una explicación hereditaria extrema. En la mayoría de los casos, la explicación correcta estará en una interacción compleja entre la herencia y el medio: la cultura es esencial, pero no podría existir sin unas facultades mentales que permiten que los seres humanos construyan y aprendan la cultura. Mi objetivo en este libro no es defender que los genes lo son todo y que la cultura no es nada-nadie cree tal cosa-" (Pinker, op. cit.) ${ }^{14}$.

${ }^{13}$ Entusiasmo que le lleva a apuntar cosas tales como que el derecho a la libertad de prensa, conforme lo recoge la constitución de Estados Unidos, está motivado por las características de la naturaleza humana.

${ }^{14}$ Eludo, en cualquier caso, comentar nada sobre el empleo de términos especialmente inseguros como "raza". 
Hay un aspecto de esta declaración que se me antoja algo ajado, ese duelo al sol entre Cultura y Naturaleza. No porque piense que "la verdad se encuentra en algún lugar intermedio", sino porque, por así expresarlo, la naturaleza humana es inmanentemente cultural. Como escribió Geertz hace ya bastante tiempo (1987 [1973]), un ser humano sin cultura ni siquiera sería un ser humano ${ }^{15}$. La cultura no está, simplemente, yuxtapuesta, o superpuesta a la naturaleza. En palabras de Lévi-Strauss (1991 [1949]: 41), "ningún análisis real permite, pues, captar el punto en que se produce el pasaje de los hechos de la naturaleza a los de la cultura, ni el mecanismo de su articulación".

Sea como fuere, la prudencia del programa en su segunda generación es aun mayor que lo perceptible en este ponderado prefacio de Pinker. El primer paso del razonamiento se da con cuidadosas precauciones. Así, cuando Tooby y Cosmides (1997) se defienden de las acusaciones formuladas por Gould (1997) -acaso la palabra adecuada sea "contraatacan"-, matizan que el adaptacionismo del programa no debe confundirse con "panadaptacionismo panglossiano", puesto que contempla las posibilidades de variaciones neutrales, o incluso desventajosas para los organismos. Ciertamente, esto elude alguna de las complicaciones de la primera generación del programa.

La selección natural, como se ha repetido innumerables veces, es una proyección del pensamiento de las ciencias sociales de su momento y su lugar sobre el mundo de los seres vivos. Es conocido, por la narración del propio Darwin, que la idea le vino inspirada por los textos de Malthus o que la expresión "supervivencia de los idóneos" está tomada de la obra de Spencer. Sea como fuere, se trata de un mecanismo que no da razón de las modificaciones experimentadas por los organismos a lo largo del tiempo, sino de su pervivencia o de su fugacidad en este planeta: un juez de última instancia que evalúa la capacidad de supervivencia de una especie, en función del diferencial reproductivo de los individuos que la componen.

Así pues, cuando se afirma que la configuración biológica es producto de la selección natural, pero que sus consecuencias bien podrían ser adaptativamente neutrales o incluso maladaptativas, resulta que la selección natural no está definida por la "supervivencia de los idóneos", sino por la de cuantos no estén demasiado mal adaptados y se puedan ir, más o menos,

${ }^{15}$ Cf. el reciente examen de García-Alonso (2009) sobre los niños salvajes. 
apañando ${ }^{16}$. Es decir, que selección acaba casi confundiéndose con la evolución, porque la segunda fase del proceso diríase que sobra en buena parte, aplicando en buena lid la navaja de Occam. Tendríamos, en definitiva, que la configuración psicobiológica humana es resultado de la evolución de las especies: algo que sólo negarían los creacionistas, de la generación que fuere, a estas alturas de la vida...Todo el pensamiento de Darwin se ha trastocado $\mathrm{y}$, si se conserva su inevitable advocación, será por motivos acaso rituales. De todas formas, es obligado decir que no hay unanimidad total en este sentido y, por ejemplo, Buss (1996) mantiene que el núcleo conceptual de la selección está en el concepto clave de adaptación.

Respecto al segundo paso del razonamiento de segunda generación, se mantiene que la conducta cultural humana es producto de bases psicobiológicas. Algo que, supongo, aceptará cualquier científico social: no es concebible cultura humana sin cerebros humanos ${ }^{17}$. Y esos cerebros son, sin duda, producto de la evolución. No es fácil, consecuentemente, ver lacras que derrumben la segunda directriz del programa en su segunda generación. Aunque tampoco es fácil ver en ella una propuesta muy enriquecedora.

Más complicaciones presenta el tercer punto. Podría ser conveniente ilustrarlas con algún ejemplo. Pinker (2004), por poner un caso, propone que la religión es una exaptación psicológica de diversos módulos, evolucionados para otros propósitos, cuyas ventajas están en ciertas satisfacciones emocionales y ciertas tendencias de nuestro aparato psíquico a experimentar la presencia de seres espirituales.

Podemos, como ejercicio, eliminar de esta hipótesis todo lo referente a exaptaciones y módulos. Nos encontraríamos, entonces, con las más antiguas propuestas de los científicos sociales ${ }^{18}$. Personalmente, no veo las ventajas que la inclusión de módulos y exepciones puede contener para dar razón de los fenómenos religiosos, cuando exactamente esa misma razón ya está dada. Nos encontraríamos - una vez más-ante un caso ejemplar de las situaciones en las que debe usarse la navaja de Occam, para descartarnos de entidades superfluas que no aportan contenido sustancial al análisis.

${ }^{16}$ Cf. Maturana y Varela (1996).

${ }^{17}$ Otra cosa, bien distinta, es que el proceder en el análisis cultural deba hacerse desde la cultura o no. Una vieja cuestión ya planteada desde, por lo menos, tiempos de Boas (2008 [1930]). Puede verse también Kroeber (1915)

${ }^{18}$ Un compendio de estas propuestas clásicas puede encontrarse en Evans-Pritchard (1998 [1965]). 
Por otro lado, el concepto de selección se basa en diferenciales. Existen unos individuos más aptos que otros y estos prolongan su material genético en el tiempo mediante las sucesivas generaciones. Una explicación darwinista debería dar una razón por la cual la creencia en seres extranaturales proporciona ventajas reproductivas a quienes la profesan. Si esas ventajas son las cosas ya dichas, y hace mucho, por Durkheim o Tylor, no logro encontrar la ventaja en colgarle a ese discurso la etiqueta "adaptativo", sólo una diferencia más relacionada con el marketing académico que con los verdaderos contenidos.

$\mathrm{Y}$ es que la propuesta de diseñar escenarios evolutivos es arriesgada. El proponer que la primera palabra fue “ipuaj!” o que las especies que dieron lugar a Homo sapiens contaban con capacidad para el canto (Mithen, 2007 [2005]) $)^{19}$, y analizar sus ventajas adaptativas, es algo que puede estar excelentemente fundado y puede ser enormemente estimulante, pero no deja de ser nítidamente especulativo. Lo mismo podría decirse del modelo Homo suadens (Castro-Nogueira et al., 2008), o de las propuestas de Buss sobre emparejamiento (1986).

Lamentablemente, y pese a las manifestaciones de Tooby y Cosmides (1997), el programa no parece suministrar teoría, sino más bien relatos post hoc completamente infalsables, como criticó en su día Gould (1997), en el debate citado anteriormente. En otras palabras (Dunbar et al., 1999: 1):

"Previously, it was difficult to apply a rigurous Darwinian analysis to so nebulous a phenomenon as behaviour. In consequence, students of animal behaviour were too often reduced to vague post hoc explanations that were largely untestable".

Por supuesto, unas hipótesis pueden estar basadas en numerosos indicios y en proposiciones lógicamente trabadas, mientras que otras no pasan de ser ingeniosas cavilaciones, y unas no tienen el mismo valor que otras. Los hallazgos de elementos fósiles, de artefactos, etc., siempre pueden proveer en el futuro de bases mucho más sólidas y elementos de falsabilidad para las hipótesis. Los modelos de Isaac $(1969 ; 1971 ; 1978)$, por poner ejemplos, sobre el comportamiento de los primeros Homo no hubieran sido más que 
imaginativas lucubraciones en tiempos del abate Breuil. Y, en ocasiones, merece la pena ser algo imprudente: es muy posible que, sin un marco imprudente en el cual colocar el trabajo de campo, jamás se hubieran aceptado las capacidades cognitivas y culturales de los chimpancés y otros póngidos.

En cualquier caso, esta tercera directriz del programa (si se consigue precisar los retos adaptativos que nuestros antepasados filogénicos tuvieron que afrontar, entonces se consigue dar razón de nuestra configuración psicobiológica) parece ofrecer una visión algo estática de los procesos evolutivos. Un rasgo seleccionado en un determinado tiempo $t$, se transforma en una presión selectiva en $t+1$, dado que, conforme a la teoría establecida, la secuencia evolutiva no tiene marcha atrás (Jolly, 1996). En consecuencia, determinado rasgo $r$, que en su día pudo representar ventajas en el diferencial reproductivo para un determinado individuo o conjunto de individuos, deja de representarlas en las generaciones subsiguientes, para formar parte de los enemigos que uno se encuentra en "la lucha por la vida", puesto que ya todos los fenotipos cuentan con el rasgo en cuestión, y el genotipo de cada individuo es un sistema caracterizado por tener como atractor su diferencial de transporte frente al de los restantes, incluyendo los de su propia especie.

Consecuentemente, si se consiguiera plantear un escenario evolutivo en el que tal o cual rasgo se instalara como producto de la selección natural (chuparse el dedo, rituales, hospitalidad o arpones, por seguir ejemplos de la compilación que recoge Pinker), sucedería que ese mismo rasgo habría dejado de tener ventajas selectivas posteriormente, para, como mucho, pasar a ser neutro. En mi opinión, este asunto parece requerir de mayor explicación en escenarios que exigen centenares de miles de años. El escenario plausible para Homo rudolfensis podría revelar ventajas selectivas en la conducta sociocultural de Homo rudolfensis, pero, para el escenario de Homo sapiens, esa misma conducta revelaría algo muy distinto, si no antagónico: presiones selectivas.

\section{Conclusión}

Parece, pues, que el fin de la segunda generación estriba en alcanzar como resultado que ciertas presiones selectivas y las dinámicas evolutivas pudieron dar lugar al rasgo de conducta sociocultural $r$ (tacañería, dar direcciones, arpones o chuparse el dedo) y que ese rasgo es general en la especie humana (incluyendo a los "primitivos"), o, más matizado, que 
nuestra configuración psicobiológica, por los mismos motivos, ha dado lugar al rasgo $r$ en cuestión.

Naturalmente, si los anhelos de Wilson de que un darwinismo en continuo cambio fagocite a las ciencias sociales -incluso a las humanas- se mantienen, el desafío es de otro tipo, no exactamente intelectual. Más bien parece relacionarse con el organigrama de facultades y departamentos de una universidad (o la organización temática de libros en una biblioteca). Pero, si se trata-como es de suponer-sencillamente de un programa de investigación darwinista, su éxito, el que produjera enormes cantidades de rasgos socioculturales de conducta más o menos adaptativos, y de raíz psicobiológica indudable, no daría razón de la porcofilia y la porcofobia, o de cómo es que los azande pretendían adivinar el futuro envenenando pollos en lugar de usar las cartas del tarot, o de que en unas sociedades los bienes se compartan y en otros se destruyan.

Los seres humanos no son tacaños o cantarines, ni siquiera son vivíparos, así, sin más. Es algo que se me antoja excesivamente platónico. Son tacaños, cantarines o vivíparos de formas determinadas. Tacañean, cantan y paren de formas culturalmente pautadas y la pregunta del millón es saber por qué en unos casos se pare de una manera (digamos, en cuclillas) y en otros, de otra (digamos, patas arriba ${ }^{20}$ ); por qué ser tacaño puede ser prestigioso o deplorable; porque en ciertas situaciones cantar es correcto y en otras es completamente intolerable. Y eso, en cualquier caso, tratando de diferencias. Porque, si se trata de semejanzas, la cuestión no es más sencilla. Fenómenos socioculturales recurrentes sólo serán efecto de las mismas causas si sus procesos diacrónicos son los mismos. Pero, cuando esas causas han de rastrearse en nebulosas pleistocénicas, sin procesos discernibles, la cosa se complica. Ante rasgos similares de conducta sociocultural, el programa exige la presunción de que tales rasgos obedecen a impulsos similares: un planteamiento perfectamente discutible y completamente apriorístico ${ }^{21}$.

La "naturaleza humana" es, sin duda, un asunto fascinante, y no lo es menos saber si lo adecuado es considerar la mente humana un libro en blanco, escrito sólo a medias, o si apenas nos caben ya unas glosas escritas en los márgenes. Pero no se trata de eso. Darwin recicló para las ciencias de

\footnotetext{
${ }^{20}$ Posición algo grotesca, desde luego, más bien producida por la organización de los sistemas expertos de salud que por la elección voluntaria de las futuras madres.

${ }^{21}$ Una vez más, véase el ya venerable texto de Boas (op. cit).
} 
la vida algunos elementos de las ciencias sociales de su tiempo: la selección, la lucha por la vida, la supervivencia de los idóneos. Y las ciencias sociales en ocasiones quieren apropiarse, en reciprocidad, de algunos elementos de la ciencia darwiniana. Cuando esos elementos tienen algo que ver con la selección, la lucha por la vida, la supervivencia de los idóneos, no hacen sino recuperar lo que fue suyo. Es como un litigio de herederos. Y, como suele ocurrir en estos casos, al final se trata de recobrar un patrimonio ya algo polvoriento.

\section{Agradecimientos}

Quiero agradecer al profesor Máximo Sandín, de la Universidad Autónoma de Madrid, y, especialmente, a mi colega del Dpto. de Antropología Social y Cultural de la UNED, Eugenia Ramírez-Goicoechea, sus comentarios sobre este texto.

\section{Referencias bibliográficas}

Boas, F. 2008 [1930]. Franz Boas: textos de antropología. Madrid, Editorial Universitaria Ramón Areces.

Brown, D. 1991. Human universals. New York, McGraw-Hill.

Buss, D. M. 1986. Preferences in human mate selection. Journal of Personality and Social Psychology, 50(3): 559-570.

Castro-Nogueira, L.; Castro-Nogueira, L.; Castro-Nogueira, M. A. 2008 ¿Quién teme a la naturaleza humana? Madrid, Tecnos.

Castrodeza, C. 2009. La darwinización del mundo. Barcelona, Herder.

Cervantes, E. 2008. El traje nuevo de Darwin: una opinión personal y otros puntos de vista sobre la teoría de rvolución por selección natural [online]. [Consultado em Dezembro, 2009]. Disponível em: http://hdl.handle.net/10261/6161.

Tooby, L.; Cosmides, L. 1997. Letter to the editor of The New York Review of Books on Stephen Jay Gould's "Darwinian fundamentalism" (June 12, 1997) and "Evolution: the pleasures of pluralism" (June 26, 1997). [online]. [Consultado em Dezembro, 2009]. Disponível em: http://cogweb.ucla.edu/Debate/ CEP_Gould.html.

Dawkins, R. 1993 [1976]. El gen egoísta: las bases biológicas de nuestra conducta. Barcelona, Salvat. 
Dennet, D. 1995. Darwin's dangerous idea: evolution and the meanings of life. London, Penguin Books.

Dobzhansky, T. 1963. Anthropology and the natural sciences: the problem of human evolution. Current Anthropology, 4(2): 138, 146-148.

Dunbar, R.; Knight, C.; Power, C. (eds.) 1999. The evolution of culture. Edinburgh, Edinburgh University Press.

Evans-Pritchard, E. E. 1988 [1965]. Las teorías de la religión primitiva. 5. edicíon. Madrid, Siglo XXI.

García-Alonso, M. 2009. El regreso de las abejas perdidas: los niños salvajes en los límites de la cultura. Revista de dialectología y tradiciones populares, 64(1): 41-60.

Geertz, C. 1987 [1973]. La interpretación de las culturas. Barcelona, Gedisa.

Gould, S. J. 2005 [1981]. La falsa medida del hombre. Barcelona, Crítica.

Gould, S. J. 1997. Evolution: the pleasures of pluralism. The New York Review of Books, 44(11): 47-52.

Gould, S. J.; Lewontin, R. C. 1979. The spandrels of San Marco and the Panglossian paradigm: a critique of the adaptationist programme. Proceedings of the Royal Society of London B, 205(1161): 581-598.

Harris, M. 1982 [1979]. El materialismo cultural. Madrid, Alianza.

International Human Genome Sequencing Consortium. 2001. International Human Genome Sequencing Consortium: Initial sequencing and analysis of the human genome. Nature, 409 (6822), pp. 860-921.

Isaac, G. L. 1969. Studies of early culture in East Africa. World Archaeology, 1(1): 1-28.

Isaac, G. L. 1971. The diet of early Man: aspects of archaeological evidence from Lower and Middle Pleistocene sites in Africa. World Archaeology, 2(3): 278-299.

Isaac, G. L. 1978. The food-sharing behaviour of protohuman Hominids. Scientific American, 238(4): 90-106.

Jolly, A. 1996. Primate communication, lies and ideas. In: Lock, A.; Peters, C. R. (eds) The handbook of human symbolic evolution. Oxford, Oxford Science Publication: 167-177.

Kroeber, A. L. 1915. Eighteen professions. American Anthropologist, 17(2): 283-288.

Kroeber, A. L. 1917. The superorganic. American Anthropologist, 19(2): 163-213.

Lakatos, I. 1998 [1978]. La metodología de los programas de investigación cientifica. Madrid, Alianza. 
Lévi-Strauss, C. 1991 [1949]. Las estructuras elementales del parentesco. Barcelona, Paidós.

Lewontin, R. C.; Rose, S.; Kamin, L. J. 1996 [1984]. No está en los genes: crítica del racismo biológico. Barcelona, Crítica.

Lock, A.; Peters, C. R. (eds.) 1996. Handbook of symbolic evolution. Oxford, Oxford Science Publication.

Maturana, H.; Varela, F. 1996 [1990]. El árbol del conocimiento: las bases biológicas del conocimiento humano. Madrid, Debate.

Mithen, S. 2007 [2005]. Los neandertales cantaban rap: los orígenes de la música y el lenguaje. Barcelona, Crítica.

Morris, D. 1971 [1967]. El mono desnudo: un estudio del animal humano. Barcelona, Plaza y Janés.

Pinker, S. 2003 [2002]. La tabla rasa: la negación moderna de la naturaleza humana, Barcelona, Paidós.

Pinker, S. 2004. The evolutionary psychology of religion. Presentation at the annual meeting of the "Freedom from Religion Foundation", Madison, Wisconsin, October 29, 2004, on receipt of "The Emperor's New Clothes Award”. [online]. [Accessed in September 2009]. Available at: http://pinker.wjh.harvard.edu/ articles/media/2004_10_29_religion.htm.

Ramírez-Goicoechea, E. 2009. Evolución, cultura y complejidad. La humanidad que se hace a sí misma. 2. a edición. Madrid, Editorial Universitaria Ramón Areces.

Ruse, M. 1989 [1980]. Sociobiología. 2. edición. Madrid, Cátedra.

Sandín, M. 2000. Sobre una redundancia: el darwinismo social. Asclepio, 52(2): 27-50.

Sahlins, M. 1982 [1976]. Uso y abuso de la biología: una crítica antropológica de la sociobiología. Madrid, Siglo XXI.

Sperber, D. 2005 [1996]. Explicar la cultura: un enfoque naturalista. Madrid, Morata.

Wilson, E. O. 1980 [1975]. Sociobiología: la nueva síntesis. Barcelona, Omega.

Woodward, V. 1982. Cociente intelectual y racismo científico. In: The Ann Arbor Science for the People, Editorial Collective (ed.). La biología como arma social. Madrid, Alhambra: 77.

Artigo recebido a 18 de Dezembro de 2009 e aceite a 4 de Junho de 2010. 